\title{
Mental health service users' experiences of returning to paid employment
}

Melanie Boyce, MSc, Researcher, Institute of Health \& Social Care, Anglia Ruskin

University, $2^{\text {nd }}$ Floor, North Building, Bishop Hall Lane, Chelmsford, Essex, CM1 1SQ

Jenny Secker, PhD, Professor of Mental Health, South Essex Partnership NHS Trust and Anglia Ruskin University, $3^{\text {rd }}$ Floor, Ashby House, Bishop Hall Lane, Chelmsford, Essex, CM1 1SQ

Robyn Johnson, BSc, Researcher, City University, 24 Chiswell Street, London EC1Y $4 \mathrm{TY}$

Mike Floyd, PhD, Professor of Disability and Rehabilitation Studies, City University, 24 Chiswell Street, London EC1Y 4TY

Bob Grove, PhD, Director of Employment Support Programme, Sainsbury Centre for Mental Health, 134 Borough High Street, London SE1 1LB

Justine Schneider, PhD, Professor of Mental Health and Social Care, University of Nottingham and Nottinghamshire Healthcare Trust, School of Sociology and Social Policy, Law and Social Sciences Building, University Park, Nottingham NG7 2RD 
Jan Slade, MSc, Senior Research Associate, The School of Applied Social Sciences, Durham University, Elvet Riverside 2, New Elvet, Durham DH1 3JT

\section{Correspondence to:}

Melanie Boyce, Anglia Ruskin University, Institute of Health and Social Care, North Building N220, Bishop Hall Lane, Chelmsford, Essex CM2 7EF m.boyce@anglia.ac.uk 08451963457 


\section{Mental health service users' experiences of returning to paid employment}

Research into mental health and employment has focused largely on people who are unemployed. This paper reports the experiences of 20 clients of employment support agencies who had succeeded in returning to work. A number of barriers to getting back to work were identified, but receiving employment support could enable people to overcome them. There was consistency with previous studies of factors associated with high and low levels of job satisfaction. Even those participants who were less satisfied with their jobs identified benefits and none described any negative effects. The quality of the employment support provided was important, including advice and counselling during the job search, enabling informed choice about disclosure, and support in work. Job retention targets are required for funding programmes in addition to placement targets. Further research into the timing and processes of disclosure and into occupation health screening processes would be helpful.

\section{Acknowledgement}

The study on which this paper is based was financed by the European Social Fund (http:www.sesami.org.uk) and six supported employment agency partners made contributions in kind. The authors gratefully acknowledge the participation of interviewees and agency staff in this study, and also the constructive contributions made by Miles Rinaldi. 


\section{Mental health service users' experiences of returning to paid employment}

\section{Introduction}

Since New Labour came to power in 1997, work and pensions policy in the UK has been dominated by the Welfare to Work agenda. Reducing the numbers of social security benefit claimants of working age has been an important goal, with a series of programmes targeted, amongst others, at disabled people, particularly those in receipt of Incapacity Benefit (IB). People diagnosed with mental health problems are less likely to be employed than other disabled people (Disability Rights Commission, 2006) and a significant proportion (40\%) of current IB claims are primarily attributed to some form of mental health problem (Department for Work \& Pensions, 2006). For this group the economic imperatives of the Welfare to Work agenda are therefore particularly pressing.

Alongside economic imperatives, employment is seen as a key means for combating the high levels of social exclusion experienced by people with mental health problems (Office of the Deputy Prime Minister, 2004) and mental health service commissioners have been urged to develop evidence-based vocational services within NHS community services (Department of Health, 2006).

To date, research has focused primarily on unemployed service users, and in particular on establishing levels of interest amongst this group in obtaining paid work, and on the type of support required for them to find and keep a job. These studies have produced valuable 
results. Surveys of mental health service users in the UK indicate that the majority of people, including those with severe and enduring mental health problems, aspire to paid employment (Bates, 1996; Rinaldi and Hill, 2000; Secker et al., 2001; South Essex User Research Group et al., 2006). In addition, a considerable body of international research indicates that employment support based on the Individual Placement and Support (IPS) approach is most effective in enabling service user to achieve their aspirations (Schneider, 2005).

However, the experiences of mental health service users who have obtained work are also important, especially in view of concerns in the US about people being placed mainly in entry level jobs which may be associated with low levels of job satisfaction and poor retention rates (Bond et al., 1997). The SESAMI (Social inclusion through Supported Employment for people with Mental Illness) study provided an opportunity to identify a sample of service users who had been supported into work and to explore their experiences of moving back into the labour market. In this paper we describe the methods used for that strand of the study and report the results. Ethics approval was granted for the study by the North West Multi-Centre Research Ethics Committee. Research governance approvals were granted by the relevant NHS Trusts where applicable.

\section{Methods}

\section{Sample}


The SESAMI study was carried out with assistance from six employment support agencies. To our knowledge the agencies, designated here as Agencies A to F, were amongst the largest providers of employment support to people with mental health problems in the UK. They included a mental health NHS Trust (Agency A), three voluntary sector agencies (Agencies B, C and D), a pan-disability organisation with contracts to implement the government's Workstep and New Deal for Disabled people (NDDP) programmes (Agency E) and an arm of the Department for Work and Pensions (DWP) that contracts out the Workstep programme under a range of brokerage arrangements (Agency F).

Between them, the agencies enabled us to recruit 182 of their clients with severe and enduring mental health problems to the SESAMI study (SESAMI research team and practice partnership, in press). At baseline, 52 participants were in paid employment in competitive, real world jobs. A further eight were in paid work, but in sheltered settings that were restricted to people with disabilities. These 60 participants were recruited from all agencies except Agency B, where no participants were in work at the time of the baseline interviews. All 60 participants were asked if they might be interested in taking part in an additional interview. Approximately six months later an information sheet describing what would be involved was sent to 33 people who had expressed an interest and 20 people consented to an interview.

\section{Data collection}


Since we were interested in exploring participants' lived experience, in-depth interviews were the data collection method of choice. A semi-structured schedule was designed to guide the interviews. This covered perceived and actual barriers to getting back to work, job satisfaction and the impact of working on participants' lives. The interviews were carried out mainly at agency premises and lasted between 40 minutes and one and a quarter hours.

\section{Data analysis}

With participants' permission, the interviews were tape-recorded and fully transcribed. Nvivo software was used to aid the organisation and retrieval of data. The transcripts were analysed thematically following the steps advocated by Miles and Huberman (1984). The first stage involved reading and rereading the individual transcripts in order to identify key descriptive and explanatory themes. These themes were then compared across transcripts to identify convergent and divergent themes. At this stage, patterns began to emerge and explanations for these were sought. The main themes relating to participants' experiences of finding and keeping a job are described below.

\section{Results}

\section{Participants and their jobs}

Almost twice as many men (13) as women (7) took part in the interviews. Seventeen of the 20 participants described themselves as White British, with two participants 
describing themselves as Asian and one as White European. Most participants had been with their agency for less than two years, but five of the Agency F participants had been receiving support for over two years, in one case for seventeen years. The average age at the time of the interview was 41 years (range $27-64$ ).

Eight participants had been supported into work under the Workstep programme or its predecessors (six by Agency F, two by Agency E) and four had received support under the NDDP programme (three from Agency D, one from Agency C). The other eight had been supported into work by their mental health NHS Trust (Agency A). The type of work participants had obtained varied (table 1). In terms of the Standard Occupational Classification (Office of National Statistics, 2000), most were working in administrative and secretarial occupations, for example as receptionists and administrative assistants. However, there was a fair representation of associate professionals, for example support workers and advocates, as well as sales and elementary occupations. Two participants, both from Agency F, were employed in sheltered settings as a machinist and depot assistant, placing them respectively in the operative and elementary occupational categories.

At interview, nine participants had been in their job for six months or less (range 6 weeks to six months), six had been in their job for between one and four years, and five had been in their job seven or more years. Those who had been in their job for seven or more years were Workstep clients who had obtained their jobs under an earlier programme, the Supported Placement Scheme. 
Table 1 about here

Thirteen of the 20 participants were actively receiving support in work from their agency. Of the other seven, two from Agency A and one from Agency D had discontinued their support as they felt they no longer needed it. The participant from Agency D received occasional letters and another participant from Agency C had had only occasional phone contact once she had started working full time. The two participants from Agency E had had little or no support in work.

\section{Perceived and actual barriers to work}

When participants were asked about the barriers they felt they had faced in getting back to work, the perceived stigma surrounding mental ill health was the most frequent response. This was associated with fears about disclosing their mental health problems to a potential employer, in some cases as a result of previous experience:

It's been my experience that people who know about it take advantage of it. (D1)

I find it difficult to tell people that I've been mentally ill, and that I need care when I do work. Usually I just go into work without telling them that I've been mentally ill, and I just get the job without being honest. (E2) 
Despite their reservations, five participants, from agencies A, C and D, had chosen to disclose their mental health problems to their employers. Three disclosed their problems on the application form, one disclosed at interview and one while awaiting occupational health clearance in order to explain the delay to the employer. In another two cases, the participants were returning to their former workplace and their employer already knew of their problems. For the eight Workstep clients, disclosure had been inevitable because being on the programme was a prerequisite for the jobs they obtained. For most people the benefits of disclosure revolved on balance around greater understanding of the problems they faced:

I think I wanted people to know that I am poorly, and that's why I behave in certain ways in certain times... I can be very, very nervous with people, and I think I needed them to make allowances for that. (E2)

I feel I would be happier because I could really be myself and not have to work so hard to make sure nobody notices that maybe I'm a little bit stressed or tired. If I said to an employer 'I'm really tired' and tiredness is one of the first triggers hopefully they would be sympathetic. (A5)

When participants did disclose their mental health history the response had been reassuring: 
The fact that [my manager] knows and this other [colleague] is nice, because they can spot it straight away. (F2)

It came up in one of our meetings I don't know why it came up but it came up and I mentioned it and she said 'Oh thank you for disclosing that', you know, 'I appreciate that'. (A1)

I felt relaxed with her anyway and just didn't see a problem with disclosing anything. (C1)

However, only three participants, one from Agency A and two Workstep clients, reported explicit discussion of adjustments at work as a result of their disclosure. In one case, it was agreed that no adjustments were required. In a second, the employee was allowed time off for meeting with her employment support worker, and in the third a plan of action should the participant become unwell at work had been agreed.

For three of the five participants who chose not to disclose, the reason was fear of losing their job. The other two were concerned to keep their work life separate from mental health issues, although one of these participants was beginning to feel more secure about disclosing now that her temporary job had been made permanent:

Now that I have got the contract maybe after a few months if I have another episode then I will tell them. (A6) 
Alongside the issue of disclosure, a disjointed employment history was seen as a major barrier to work for participants who were not on the Workstep programme, and some participants singled this out as the key barrier:

If you've got a big gap on your CV or when filling in an application form then it can be very troublesome, can't it, trying to explain that gap? (D3)

Most of these participants had received support to find constructive ways of dealing with gaps in their CV and, as with disclosure, their employment history had not in the event proved to be a barrier:

Because I've been through the course and all that I was able to actually portray it in a positive light and say, 'Well, yeah, because I've had this time off work I now know that I'm ready to go back and I've had a chance to really look at what I want to do...'. They could see that I'd got a four-year gap between my employment but they didn't even ask me about it, what they were interested in was how I was going to be able to deal with the job now. (C1)

On the other hand, an unanticipated barrier did arise for three participants in the process of starting work, namely the problems involved in obtaining occupational health clearance: 
The only thing that was holding it up was the occupational health. I mean I was really worried about that, that it was not going to go in my favour and I was going to be told that I couldn't, you know, start. It annoyed me because they gave me this appointment which took weeks to come through... (A1)

I actually had to go for an appointment with the occupational health doctor and he threw up just absolutely everything that was negative about my past anything that he could see could be a problem he threw up as a problem. He didn't look at it as well you know you've just done two months of very intensive work and you've come out of that, you've done voluntary work, you've done training before that, it was just a case of well you haven't worked for the past five years how do you think you're going to cope with a full time job... Fortunately I was strong enough and knew how to come back with a positive every time but had I not been as strong as I was to be honest it would have reduced me to tears.

\section{Job satisfaction}

Nine of the 20 interview participants were very positive about their job and felt that it suited them well, although some did aspire to developing their career further within their organisation. Most other participants thought their job was 'ok' and enjoyed some aspects, but also described some problems. With the exception of the two Agency E participants, both of whom were experiencing considerable problems and were 
considering leaving their job, positive and less positive views were fairly evenly spread across the agencies. The positive views are considered first below, followed by the problems described by some participants.

\section{Positive views}

Factors associated with job satisfaction included the right balance for the individual between work demands and sufficient challenge, a sense of achievement and using and expanding work skills:

That's what I enjoy - If you're not thinking you're not alive are you? (A4)

I just love dealing with the public... You feel that you're actually pleasing people and helping them and they appreciate that and you can see it. (F3)

There was never set any challenges before because I was always held back, because of my illiteracy problem... I don't really want to sound boastful or anything, but I can do most, well, all the jobs now in the factory, and I can teach people, which I'm prepared to do. And that gives me a lot of pleasure, teaching people, I can pass on my skills to another person, I think that's good. (F6) 
A supportive workplace was also very important. Understanding managers or supervisors played a central role in this respect, and supportive colleagues were also singled out for comment:

She's the type of person you could go to and just talk about anything... it's very relaxed and so if there's a problem and I could go and talk to her. (C1)

My supervisor ... is very, you know, helpful and supportive whenever I've had any problems. Like I was depressed, um, last year about October time and I have taken a few days off work and she was really understanding about it and really supportive. (A1)

I like how all the staff gets together like a big family, we all bounce off each other...we go out for a drink and a laugh. (A3)

They are very supportive and the people are just the best. (A6)

\section{Problems at work}

The less positive views expressed by some participants revolved around discrimination, working conditions, lack of support and the impact of mental health problems on work. Amongst our sample, only the two Agency E participants described discriminatory attitudes at work: 
The odd comments that he has made have been snidey, rather than supportive and helpful, 'you're not the full shilling' and things like that, it's all very hurtful. (E2)

I'm concerned about the levels of discrimination between people, who, for want of a better word, you could call the real [employer's] staff, and the rest of us who were only the [Agency E] people ... When you're thinking you're equally qualified to do the same job, but someone's getting $£ 17,000$ and you're getting $£ 11,000$, you're thinking, does that qualify as discrimination? (E1)

The first Agency E participant quoted above also found her working conditions difficult. Although her employment support worker had been present when the terms were agreed, they appeared to contravene employment law:

He [manager] just said when can you start, there are so many hours, and I don't give breaks. And I thought well, he's got to be joking, not getting breaks. But he wasn't. And that was it. That was the interview.

Researcher: Was [employment support worker] there?

Yes.

Researcher: And [employment support worker] heard him say he didn't give breaks?

Yes

Researcher: How many hours do you work?

Eight and a half hours a day. 
Researcher: Not without a break?

Yes.

Two other participants reported that they sometimes felt isolated at work, and both thought it would be better for their mental health if they were less isolated. Most of the remaining participants who were less satisfied with their jobs described their work as monotonous or boring. For one person the problem was one of monotony combined with the frustration of being reliant on colleagues to deliver information on time:

It can get monotonous. Sometimes, the worst thing I think is the fact that I have to request lots of information from people and if they don't return it on time then I have to chase them up. Then I get into trouble... So it is stressful. (A6)

However, participants tended to accept these less than ideal working conditions because their jobs did have advantages, such as being close to home and convenient.

Where participants described unsupportive work environments, this was associated with insufficient training on starting work, high job demands in the absence of a job description and conflicting demands:

I was thrown in the deep end with doing things when I didn't know enough of what I was doing. (A2) 
On a practical level or to put it one way it would help if my bosses gave me a job description and we both stuck to it. (D1)

The young supervisors who have authority and power in the job they kind of, you know, they... even if you're not on their department they'll make you do work for them. My other line manager says he's not allowed to take you off the floor so it's complications like that so you know. (A3)

Finally, four participants attributed dissatisfaction or difficulties with aspects of their job to their own mental health problems. The issues raised concerned high levels of anxiety about supervision (A1), underachievement (F1), social anxiety (A8) and the need to take time off work (A6). These four participants were reluctant to discuss the issues with their manager, in three cases despite having disclosed their mental health problems.

\section{The impact of work on participants' lives}

All participants identified positive impacts that working had had on their lives, including those who were dissatisfied with their job in some way. Many felt that working was helping them to deal with their mental health problems, improving their self-esteem and inspiring optimism about the future:

I feel more stable in my head...to have a job now is very good and only more positive things can come out of it. (A3) 
I'm not as shy as I used to be. I am more outgoing. I can talk to people, whereas before I just used to shy away and just sit in the house nearly all the time... I might not have been here if I hadn't got a job. (C1)

These positive impacts appeared to centre around five factors: a more structured day, making a contribution, a sense of achievement, social contact and financial rewards.

Participants who highlighted the benefits of having a more structured day appreciated being able to go to work 'instead of just being stuck in my flat', as one person put it. Staying at home was perceived to exacerbate mental health problems, whereas going into a workplace helped them to minimise their symptoms:

It's something to keep me going, I couldn't stay at home, I'd get very, very bored, and I'd go backwards with my health...I have some friends that I've known for a long time there, so that keeps me going, somehow get the motivation to get up, or I'd otherwise sleep all the time. (F1)

It was also evidently very important to participants to feel that they were making a contribution to society through working:

I have a strong work ethic...you have no feelings of self worth or value if you don't work. (A4) 
In addition, several people felt that having what one person described as 'ordinary contact' with others at work - colleagues or customers - was a major factor in their improvement, as was the sense of achievement working provided:

It's really good to feel normal. It's such a difference. The world of the ill and the world of the sane. Two different worlds. Yeah. It feels great. (A6)

I feel satisfied at the end of the day. It gives you something to live for really doesn't it? (D2)

Although apparently not a major factor for many people, five participants did highlight the benefits of the financial rewards brought by employment:

It's great having my own money coming in - earning, you know, earning the money that I'm living on rather than getting it from the state. $(\mathrm{C} 1)$

\section{Discussion}

This was a small scale qualitative study designed as one strand of an extensive mixed methods study. The findings cannot therefore be generalised to the experiences of other people with mental health problems who have succeeded in getting back to work. Nevertheless, in several respects the results do echo those of other research, strengthening 
their validity, while in other respects they highlight new issues that would benefit from further attention.

The range of jobs participants had been able to obtain was encouraging. In contrast with experience in the United States (Bond et al., 1997), only four participants were in entry level jobs and this was representative of all 60 people in work at the time of the SESAMI baseline interviews, amongst whom only 14 (23.7\%) were in entry level jobs (SESAMI research team and practice partnership, in press)).

There was also consistency with previous studies of factors associated with high and low levels of job satisfaction. Excessive demands, monotony, a lack of control over workload or work pace, unsupportive managers and colleagues, and lack of role clarity have all been associated with work related stress and low levels of job satisfaction (Mackay et al., 2004). These factors were clearly reflected in the accounts of participants who were experiencing problems at work, while their corollary in terms of the right balance between demands and challenge and a supportive work environment were evident in the more positive views expressed.

Equally, the benefits of work participants described, including improved mental health, self-esteem, achievement, social contact and financial rewards have long been recognised as important (Jahoda 1982). Even those participants who were less satisfied with their jobs identified benefits and none described any negative effects. Our study therefore suggests that people with severe and enduring mental health problems can realistically 
aspire to a range of types of work, that the satisfaction and benefits they derive from work are no different than for anyone else, and that work need not have the negative impact feared by some mental health professionals.

The perceived barriers to work relating to disclosure of mental health problems and disjointed work histories echo those described elsewhere (Secker et al. 2001; South Essex User Research Group et al., 2006). What is of particular interest is that some participants had been able to overcome those barriers and had met with a positive response from their employer. Similarly, Ellison et al. (2003) infer from the proportion of respondents to their national US survey who had no regrets about disclosure that overall the experience had been positive. In the US study, two fifth of those who had disclosed did so after some time in their job when they felt more secure about doing so. One participant in this study was also considering disclosure since her job had been made permanent, suggesting that longitudinal research might shed more light on the processes and outcomes of disclosure.

In this study, it was clear that some employment support workers had played a key part in enabling their clients to make an informed choice about disclosure at an early stage in their return to work and to reframe gaps in their work history positively. These elements of employment support are consistent with descriptions elsewhere of effective employment support for people with severe mental health problems (Bond et al., 1997; Becker and Drake, 2003). Although the decision about disclosure is always an individual one, positive experiences like those described to us and reported by Ellison et al. (2003) might encourage other service users to take this step, with advice and support, thus 
increasing the possibility of reasonable adjustments and other entitlements under the Disability Discrimination Act.

One difference between the barriers identified by participants in this study and those identified in previous studies concerns the lack of importance ascribed by the interviewees in this study to financial issues, and particularly the lack of any mention of the risk of losing welfare benefits. It may be that benefit issues had never been a major concern for our sample. On the other hand, benefit issues may have initially been a concern, as they were for a number of unemployed people in the wider SESAMI study (SESAMI research team and practice partnership, in press), but one that had faded as participants found jobs that suited their financial situation.

A barrier highlighted by our study that does not previously appear to have been documented concerns occupational health procedures. The accounts of three participants demonstrated that disclosure of mental health problems on occupational screening forms can set in motion a complex, time consuming and anxiety provoking chain of events. We have no way of knowing from this sample how many other aspiring employees were deterred or ultimately rejected by their employer's occupational health service, nor whether the delays described by some reflect particularly stringent practices where mental health problems are concerned, compared with other disabilities. The gatekeeping role of occupational health is crucial in giving people living with mental health problems access to paid work, yet this does not appear to be an issue that is currently addressed either in research, or in the employment support literature. 
A key element of effective employment support which is well documented, follow up support in work, was missing for seven participants. Although this was by mutual agreement in three cases, in four cases it appeared to be related to agency funding criteria or other resource issues. Several of the seven clients were amongst those who described difficult working conditions which might have been addressed if support had been available. The working conditions described by one Agency E participant, which appeared to contravene employment law, were clearly of particular concern, but those participants who were finding their work monotonous might also have benefited from support with career review and development.

Where follow up support was available it was greatly appreciated, particularly in respect of negotiation of workplace adjustments. However, it appeared that key issues were not always discussed with employment support workers. In particular, three of the four participants who described mental health problems were receiving support in work from an agency but this did not appear to be addressing the implications of their mental health problems for work. It may be that the employment support workers did not see themselves as qualified to offer advice on mental health issues. The emphasis placed by agencies on work-focused support may have resulted in approaches which ignored or failed to address ongoing mental health issues. It may also be possible that participants did not see their employment support worker's role as relevant to their mental health problems, so they did not raise these issues with that person. 


\section{Conclusions}

Our study of the experiences of 20 people with severe and enduring mental health problems who had paid work indicates that this group should not be excluded from employment support programmes on the grounds that they will be unable to work, or that work will be harmful for them. Nor should they be discouraged from exploring the suitability of a range of types of work, beyond entry level jobs.

The quality of the employment support provided is, however, central. Before getting a job, an individual has to overcome the psychological barriers and the perceived stigma associated with mental illness, not to mention the benefits trap, so advice and counselling at this stage is fundamental. Enabling people to make an informed choice about disclosing their mental health history is another important element of the employment support worker's role at the recruitment stage, but this may also be important at later stages for those who choose not to disclose on applying or at interview. Further research into the timing, processes and outcomes of disclosure would shed light on this issue.

Ongoing support in work to deal with problems should they arise is also valuable where this is wanted by the individual. Whether or not a person chooses to disclose their mental health history to their employer, fostering career development could be as important for some people as enabling them to resolve problems at work. It may also be helpful for employment support workers to explore proactively any work-related impact of ongoing mental health problems, since the findings reported here indicate that people might not 
raise these issues themselves. When people choose to disclose their mental health problems to their employer, identifying and negotiating any adjustments required under the Disability Discrimination Act is a further key role, and one which might require a more planned and direct approach than appeared to be the case for some study participants.

Many, if not most, employment support funding programmes, including the New Deal for Disabled People and Workstep have set targets for job placements or work trials. The considerations raised by these interviews, which underline a need for long term, responsive involvement from the employment support worker, seems to favour funding arrangements which focus on job quality, worker satisfaction, length of job tenure and career development, rather than only on placement targets.

The barriers which appear to be posed in some cases by occupational health screening processes do not appear to have been documented previously and further research is required to ascertain whether people with mental health problems experience greater delays and rejection rates than people with other disabilities. Occupational health physicians, who mainly work for large organisations, may regard their duty as upholding the interests of the employer and the employer's insurer versus the job applicant. While experience at one English Mental Health NHS Trust indicates that liaison between employment support workers and occupational health professionals can help circumvent the problems described ${ }^{1}$, the potential for co-operation may be more restricted in the private sector. Employment support workers need to understand the part played by

\footnotetext{
${ }^{1}$ For further information contact Sue.French@ southessex-trust.nhs.uk
} 
occupational health in each case, and may find it constructive to work towards a trusting working relationship with occupational health departments in their area. 


\section{References}

Bates, P. (1996) Stuff as dreams are made on. Health Service Journal 4th April: 33.

Becker, D.R., \& Drake, R.E. (2003). A working life for people with severe mental illness. Oxford: Oxford University Press.

Bond G, Drake R, Mueser K et al. (1997) An update on supported employment for people with severe mental illness. Psychiatric Services 48(3): 335-346.

Department for Work \& Pensions (2006) A New Deal for Welfare: Empowering People to Work. London, Department for Work and Pensions.

Department of Health (2006) Vocational services for people with severe mental health problems: commissioning guidance. London: Department of Health.

Disability Rights Commission (2006) Disability Briefing., March 2006. www.drcgb.org/library/research/drc_disability_briefing/disability_briefing_march_2006.aspx Accessed August 2006.

Ellison M., Russinova Z., MacDonald-Wilson K. and Lyass A. (2003) Patterns and correlates of workplace disclosure among professionals and managers with psychiatric conditions. Journal of Vocational Rehabilitation 18: 3 - 13. 
Jahoda, M. (1982). Employment and unemployment: a social-psychological analysis. Cambridge University Press.

Mackay C., Cousins R., Kelly P., Lee S. and McCaig R. (2004) 'Management standards' and work related stress in the UK: policy background and science. Work \& Stress 18: 2: $91-112$

Miles, M. \& Huberman, M.A. (1984). Qualitative data analysis. Beverley Hills: Sage Publications.

Office of the Deputy Prime Minister (2004) Mental Health and Social Exclusion: Social Exclusion Unit Report. Office of the Deputy Prime Minister, London.

Office of National Statistics (2000) Standard Occupational Classifications 2000. Office for National Statistics, London, The Stationery Office.

Rinaldi, M. \& Hill, R. (2000) Insufficient Concern. Merton Mind, London.

Secker J., Grove B. \& Seebohm P. (2001) Challenging barriers to employment, training and education for mental health service users: the service user's perspective. Journal of Mental Health. 10: 4: 395-404. 
Schneider, J. (2005) Getting back to work: what do we know about what works? In B. Grove, J. Secker and P. Seebohm (Eds.) New thinking about employment and mental health: 37-49 Oxford: Radcliffe.

SESAMI research team and practice partnership (in press) The SESAMI evaluation of employment support in the UK: Background and baseline data. Journal of Mental Health.

Secker J., Grove B. \& Seebohm P. (2001) Challenging barriers to employment, training and education for mental health service users: the service user's perspective. Journal of Mental Health. 10: 4: 395-404.

South Essex Service User Research Group, Secker, J. and Gelling, L. (2006) Still dreaming: service users' employment, education \& training goals. Journal of Mental Health 15: 1: 103-111. 
Table 1 Occupational categories

\begin{tabular}{|lc|}
\hline Professional occupations & 1 \\
\hline Associate professional and technical occupations & 4 \\
\hline Administrative and secretarial occupations & 5 \\
\hline Skilled trade occupations & 1 \\
\hline Personal service occupations & 1 \\
\hline Sales and customer service occupations & 3 \\
\hline Process, plant and machine operatives & 1 \\
\hline Elementary occupations & 4 \\
\hline
\end{tabular}

